\title{
End-of-life decision making in respiratory failure. The therapeutic choices in chronic respiratory failure in a 7-item questionnaire
}

\author{
Dagmar Elfriede Rinnenburger, Mario Giuseppe Alma, Domenico Bigioni, Giuseppe Brunetti, Carlo \\ Liberati, Vinicio Magliacani, Gianluca Monaco, Lino Reggiani, Giovanni Taronna and Luca Cecchini \\ Unità Operativa STIRS, Ospedale San Camillo-Forlanini, Rome, Italy
}

\begin{abstract}
Introduction. The transition from paternalistic medicine to a healthcare culture centred on the patient's decision making autonomy presents problems of communication and understanding. Chronic respiratory failure challenges patients, their families and caregivers with important choices, such as invasive and non-invasive mechanical ventilation and tracheostomy, which, especially in the case of neuromuscular diseases, can significantly postpone the end of life. Material and Methods. A 7-item questionnaire was administered to 100 patients with advanced COPD, neuromuscular diseases and pulmonary fibrosis, all of them on oxygen therapy and receiving day-hospital treatment for respiratory failure. The objective was to find out whether or not patients, if faced with a deterioration of their health condition, would want to take part in the decision making process and, if so, how and with whom. Results. Results showed that: $90 \%$ of patients wanted to be interviewed, $10 \%$ preferred not to be interviewed, $82 \%$ wanted to be regularly updated on their clinical situation, $75 \%$ wanted to be intubated, if necessary, and $56 \%$ would also agree to have a tracheostomy. These choices have been confirmed one year later, with $93 \%$ of respondents accepting the questionnaire and considering it useful. Conclusions. It is possible to conclude that a simple questionnaire can be a useful tool contributing to therapeutic decision making in respiratory failure.
\end{abstract}

Key words: chronic respiratory failure, COPD, neuromuscular diseases, pulmonary fibrosis, therapeutic decisions, intubation, tracheostomy, end of life.

Riassunto (Le decisioni di fine vita nell'insufficienza respiratoria cronica. Le scelte terapeutiche in un questionario di 7 domande). Introduzione. Il cambio dalla medicina paternalistica verso una cultura della salute centrata sull'autonomia decisionale del paziente genera problemi di comunicazione e comprensione. L'insufficienza respiratoria cronica sfida i pazienti, le loro famiglie e i curanti con scelte importanti come la ventilazione meccanica non invasiva o invasiva, che nelle malattie neuromuscolari può notevolmente posticipare la fine della vita. Materiali e Metodi. Un questionario (STIR - Scelte Terapeutiche nell'Insufficienza Respiratoria) con 7 domande è stato somministrato a 100 pazienti con BPCO avanzata, fibrosi polmonare o una malattia neuromuscolare, tutti in ossigenoterapia a lungo termine e in cura presso il Day Hospital. L'obiettivo era di capire se i pazienti con un peggioramento delle loro condizioni di salute volevano partecipare nei processi decisionali e, se sì, come e con chi. Risultati. 90\% volevano essere intervistati, il 10\% rifiuta di partecipare; $82 \%$ vuole essere informato regolarmente sulle proprie condizioni di salute, $75 \%$ vuole essere intubato, se necessario, e il 56\% accetterebbe anche la tracheostomia. Queste scelte sono state confermate dopo un anno, con 93\% di pazienti che accettavano il questionario e lo consideravano utile. Conclusioni. Un semplice questionario può essere un mezzo di aiuto utile nelle decisioni terapeutiche nell'insufficienza respiratoria cronica avanzata.

Parole chiave: insufficienza respiratoria cronica, BPCO, malattie neuromuscolari, fibrosi polmonari, decisioni terapeutiche, intubazione, tracheostomia, fine vita.

\section{INTRODUCTION}

End-of-life decision making in medical practice is not a simple or straightforward process. It involves not only legal, but also ethical obligations. In addition to the long-standing ethical principle requiring doctors not to deliberately end patients' lives, a new obligation is now recognized to respect individual autonomy. Today, patients themselves should be en- titled to make independent decisions about ending their own lives or having them prolonged, as long as they are aware of the deficits they might experience. Information and counselling are crucial in helping patients to make their decisions. As a result, it is no longer possible not to talk about end-of-life issues and the related decision making process in chronic respiratory failure. 
This new perspective brings about an epocal change compared to the paternalistic medicine of the past, which left such decisions to the physicians, according to their "science and conscience". Although the traditional paternalistic model and the underlying medical ethics are still widespread in our society, a change in the doctor-patient relationship was inevitable.

An outline of the new model is provided in article 38 of the Code of Conduct of Italian Doctors (2006), Citizens' autonomy and advance healthcare directives:

"Doctors shall, without prejudice to their professional autonomy and independence, respect their patients' freely expressed will to be treated, and act with due regard for their dignity, freedom and autonomy.

Doctors shall, depending on their minor patients' age, capacity for understanding and maturity, provide them with adequate information and take their will into account.

If irreconcilable differences emerge with the demands of their patients' legal representatives, doctors shall report the case to judicial authorities; doctors shall do the same when dealing with mentally ill adults.

If patients are unable to express their own will, doctors' decisions shall take into account any previous confirmed and documented statement made by the patients themselves".

We will not discuss the possible implications of the wording "confirmed and documented" (does it refer to a statement made before a notary? A written document countersigned by the general practioner?). If we leave issues of form out of the equation, the actual message is clear: the patient's will - and not their relatives' - is essential for a medical decision to be considered ethically justifiable.

Discussing with patients their possible prognosis and the decisions they might have to make, since the beginning of their journey through the disease, is difficult and painful; but necessary to guide them in their decision making process. Nobody, when in good health, would like to picture himself either tracheostomized nor ventilator dependent or both. A "living will" does make sense only for some persons in the early stages of a disease, for many decision making is a lengthy and gradual process with the temptation to try to remove the real situation.

This is true for all degenerative neurological diseases, and especially for chronic respiratory failure. Like other chronic progressive diseases, it often requires constant decision making. In amyotrophic lateral sclerosis, for example, problems often start with the purchase of a walking frame or a wheelchair, as mobility becomes more difficult: accepting a wheelchair is psychologically hard. As the disease progresses, patients may be asked to agree to have a PEG tube inserted, when nutrition is no longer sufficient due to increased swallowing difficulties. Later on, or at the same time, they are faced with the decision of whether or not to receive mechanical ventilation, starting, when possible, with non-invasive ven- tilation. Then, the most difficult decision has to be made, as it is crucial to ensuring long-term survival: tracheostomy or palliative treatment.

Everybody who takes care of ALS patients knows how painful such decisions are and how difficult communication with families can be. Today, patients are often well-informed, they surf the Internet and visit the websites of patients' associations. Relationships between patients and their families and friends are often quite complex. It may happen that relatives want to protect the patient or that the patient adopts a protective attitude towards their family. In both cases, power relations, including power expressed through care and protection, end up interfering with decision making.

Considering end-of-life options in the short term is unbearable to many. Some patients are not able to make decisions in advance, especially when they are forced to choose between death and a restricted life. There are people who desire to prolong life at all costs and other who refuse categorically. How can we help to make decisions that respect individual differences?

Issues concerning advance healthcare directives play a role in this context. A clinical case study can help to figure out the problem raised in the medical practice.

A 38-year-old patient with amyotrophic lateral sclerosis (ALS) is admitted to the emergency department in a lethargic state induced by hypercapnia. The patient's wife claims her husband doesn't want to be intubated; there are no other witnesses, nor written statements. The anaesthetist intubates the patient. Once the patient's respiratory function is stabilized, the anaesthetist wakes him up and asks his opinion. The patient, a father of two small children, says he wants to live and agrees to tracheostomy and longterm ventilation. Did he change his mind or had he all along disagreed with his wife's opinion? We will never know. However, it is clear to us that, in principle, the final decision should rest with the patients (not the family nor the doctor) who certainly have their own opinions and preferences as to whether or not to spend the rest of their lives on ventilation.

An advance directive would have solved the problem? A growing interest in these issues is becoming evident in Europe, where epidemiological studies on end-of-life (ELD) decisions have been conducted for years. A European study (Eureld) [1] carried out in 2001-2002 was published in The Lancet one year later [2]. The research project was aimed at investigating to what extent end-of-life decision making practices varied in six European countries. Researchers found that, during the period of the study, about one third of all deaths happened suddenly and unexpectedly in all participating countries. Over half of all remaining deaths were preceded by medical end-of-life decisions. The second part of the study was conducted some months later and focused on doctors' views about end-of-life decision making. Differences in their opinions were consistent with their different practices. 
A similar research, promoted by the Italian Federation of Medical Associations and aimed at investigating doctors' end-of-life care practices and their views on these issues, was carried out in Italy in 2007 (ITAELD) [3]. The most significant finding for Italy is the increasing medicalization of the dying process, previously observed at the European level by the Eureld study: about 1 in 4 deaths is preceeded by medical decisions intended to hasten death, or not prolong life. These practices include end-of-life care (like pain management and continuous deep sedation), medically-assisted death (assisted suicide and euthanasia), and non-treatment decisions (withdrawing or withholding treatment; discontinuing treatment). Ethical considerations on the various practices and doctors' views on key issues like patients' right to hasten their death differ notably. However, there is a trend towards favouring patients' autonomy in decision making.

According to an Italian 2001 study [4], 17 out of $34(50 \%)$ neurological centres reported dealing with respiratory paralysis ("end-of-life issues"); 15 out of $34(44 \%)$ said they proposed invasive ventilation, while 22 of $34(65 \%)$ proposed non-invasive ventilation as therapeutic options. These surprising data suggest that, in 2001, invasive ventilation and lifeprolonging measures were proposed to only half of the patients, while everybody needed it.

The biggest change is the introduction of a new perspective: even more important than what the doctor proposes or does not propose is the opportunity given to the patient to make their own decisions based on their values and preferences.

The new decision making paradigm becomes especially important in a disease like ALS, because of the sometimes rapidly progressive disease, but is important as well for end stage chronic obstructive pulmonary disease (COPD) patients. Three limitsituations prompt us to question traditional decision making processes:

- too often, patients with ALS are not informed of their respiratory paralysis and can't make a decision about it;

- too often, intensive care doctors are forced to make decisions, despite having no information about the patients' will;

- too often, doctors and relatives make decisions against the patients' will: patients who had refused ventilation eventually had a tracheostomy, and others who wanted to survive respiratory paralysis died without receiving ventilation.

The public's interest in ALS is well-known. The fact that a number of celebrities (especially from the world of sport) had ALS brought the disease to a high attention in the media. The ethical issues raised by ALS are particularly suitable to illustrate the head-on clash between catholic thought and the secular stance, which underlies the bioethical debate in Italy. The religious stance is centred on the principle of the "sanctity" of life and advocates that treatments be extended indefinitely, although that includes what many describe as extraordinary measures to prolong life. The secular stance prioritizes the patient's will and their right to set limits to treatments.

Decision making in COPD has traditionally generated a less passionate debate. However, considering the high number of COPD patients and the dramatic choices they also may be faced with, they are included in the study, being sometimes forced to decide between quantity and quality of life.

In the UK, COPD and/or an acute exacerbation of COPD account for $10 \%$ of all hospital admissions. Mortality during hospital stay is $11 \%$. Respiratory diseases account for $20 \%$ of deaths each year [5].

COPD is a serious high-mortality disease: after five years, mortality among patients with severe COPD is $50 \%$, and rises to $60 \%$ if patients are in intensive care and on mechanical ventilation. Overall, $83 \%$ of patients with severe COPD have never shared their end-of-life decisions with their doctors [6]. At present, end-of-life decisions in respiratory diseases and COPD are made by doctors, and decisions about intubation and tracheostomy are never discussed with patients.

Views on whether or not to intubate a patient differ considerably among doctors and the prognosis is uncertain [7]. As a result, doctors don't dare to raise end-of-life issues and patients wait for doctors to do so. In the US, this situation is often referred to as "the deadlock in end-of-life-communication"[8].

At the Respiratory Intensive Care Unit for Patients with Respiratory failure of the San Camillo Hospital (Rome), like in other hospital environments, therapeutic choices have often been the subject of heated debates based on the personal opinions and preferences of the treating healthcare professionals. To achieve a different and patient centered perspective, it was agreed to use a questionnaire called "Therapeutic Choices in Respiratory Failure" (Scelte Terapeutiche nell'Insufficienza Respiratoria, STIR).

What makes this study different is that patients in a stable phase of their disease were directly asked what choices they would make if their condition worsened. A preliminary question was asked to verify patients' willingness to take part in the study. Researchers had to deal with a long-standing cultural issue: are Italian patients willing to speak about treatment options and decision making in emergency situation, when they are in a stable phase of their disease, or would they rather not be involved and rely on somebody else's (doctors, relatives) choices?

\section{MATERIALS AND METHODS}

The Day Hospital of the intensive care unit "Stirs" at the San Camillo Hospital of Rome is attended only by patients with advanced respiratory failure in longterm oxygen therapy of various origins. Patients come for a control visit normally once a month. They are chronic patients and know their physicians for a long time, sometimes years. 
We started to include patients in the beginning of 2006 and stopped after having included 100 after a few months. All patients being in longterm oxygentherapy for various reasons were admitted. The only exclusion criteria were a cognitive impairment like dementia or a very advanced stage of the disease with $24 \mathrm{~h} / 24$ ventilation in neuromuscular diseases like amyotrophic lateral sclerosis with difficulties in verbal communication.

A 7-item questionnaire called Therapeutic Choices in Respiratory Failure (Scelte Terapeutiche nell'Insufficienza Respiratoria, STIR) was developed. The first preliminary question was if the person really wanted to participate in this emotionally difficult questionnaire. And the patients refusing to go on were excluded from answering the other questions.

Preliminary question: Are you willing to take a questionnaire on end-of-life decisions?

- NO; 10 patients refused to continue the questionnaire.

- YES; 90 agreed to answer the questionnaire (including the 6 patients with tracheostomy).

The other seven questions regarded the wish to participate in therapeutical decision making, the wish to be updated regularly, the difficulties in accepting therapeutic choices already taken, the consense for intubation, if necessary, the consense for tracheostomy and the wish of company or loneliness in the last part of their lives.

The questionnaire was administered by 4 different physicians to 90 patients (6 of whom with tracheostomy) on long-term oxygen therapy. All patients were receiving day hospital treatment (once a month).

The diagnosis were distributed like following (including the patients refusing to go on after the preliminary question):

- COPD: 84 (84\%), average age (67);

- pulmonary fibrosis: 8 (8\%), average age (68);

- neuromuscular diseases: 8 (8\%), average age (45).

Only 2 of hundred were still working, all the others were retired from work because of age or disease invalidity.

In 2007, one year after the first distribution of the questionnaire, we proposed the same questionnaire to the patients that we were able to contact and who had been interviewed one year before.

It was possibile to contact 57 of the 93 patients of 2006. It was impossible to contact 26.

\section{RESULTS}

The analysis of the answers to the seven questions of the multiple choice questionnaire shows us the following results:

\section{Question 1}

Therapeutic or care choices affecting you may have to be made during the treatment (decisions about hospital admission, medical tests, therapies). Would you like to be involved in the decision making process, alongside doctors, or would you rather delegate decisions to others?
1- I'll share in decision making with family (or people I trust) and doctors $\quad 54(60.0 \%)$

2- I'll share in decision making with doctors $27(30.0 \%)$

3 - Family and doctors $5(5.6 \%)$

4- Others (e.g., nuns ) $2(2.2 \%)$

5 - I'll delegate decisions to doctors $1(1.1 \%)$

6- I don't want to decide

$1(1.1 \%)$

\section{Question 2}

Would you like to be regularly updated on your clinical situation and the progress of your disease?

1- I want to be regularly informed $74(82.3 \%)$

2- I want to be informed only if I ask to $\quad 6(6.7 \%)$

3 - I want to be informed if I ask to and doctors deem it necessary

$5(5.6 \%)$

4- I want to be informed only if doctors deem it necessary

5- I don't want to be informed

6- Didn't answer

\section{Question 3}

The use of special equipment and procedures may be required as part of our care. Did you find it difficult to accept oxygen therapy with a nasal cannula or a Venturi mask, or non-invasive mechanical ventilation?

1- Yes

$58(64.5 \%)$

2- No

$28(31.1 \%)$

3- Didn't answer $4(4.4 \%)$

\section{Question 4}

If respiratory failure rapidly develops, intubation may be necessary to provide more effective ventilation. Would you agree to this procedure? no. $=84$ $(100 \%)^{*}$

$1-Y e s$

$63(75 \%)$

2- $\mathrm{No}$

$11(13.1 \%)$

3- I don't know

$8(9.5 \%)$

4- I don't want to decide

$2(2.4 \%)$

\section{Question 5}

Sometimes, when non-invasive ventilation is no longer effective or cannot be performed due to other reasons, tracheostomy may be necessary with the subsequent insertion of an endotracheal tube connected to a ventilator.

Would you agree to this procedure? no. $=84(100 \%)^{*}$

$1-$ Yes

2- No $47(55.9 \%)$

3- I don't know

$25(29.8 \%)$

4- I don't want to decide

$9(10.7 \%)$

$3(3.6 \%)$

\section{Question 6}

If needed, who would you prefer to look after you most of the time: your family (or friends) or qualified professionals (nurses)?

1- Family and friends

2- Professionals

$34(37.8 \%)$

3- I don't care $9(10 \%)$

*excluding patients with tracheostomy. 


\section{Question 7}

In the most difficult moments of your disease would you prefer to have somebody close to you or do you prefer to stay alone:

1. I would like to have somebody close to me: 65 $(72.2 \%)$

2. I prefer to stay alone: $19(21.1 \%)$

3. It doesn't matter if I'm alone or in company: 6 $(6.7 \%)$

One year later, a follow-up questionnaire was administered to compare data. It was possible to contact 57 of the 90 patients interviewed the year before.

Most of the patients confirmed their previous choices.

- $34(60 \%)$ want to make all decisions together with their families and doctors; 17 (30\%) want to make all decisions together with doctors

- $47(82 \%)$ want to be regularly informed

- 44 out of 52 (57-5 patients with tracheostomy) $(85 \%)$ would want to be intubated; $5(8.8 \%)$ would refuse intubation; 3 refuse to decide

- $35(67 \%)$ would have a tracheostomy; $11(21 \%)$ would refuse tracheostomy; $6(12 \%)$ don't want to decide

One patient who had said, during the first interview, that he would refuse tracheostomy, had changed his mind.

All of the 5 tracheostomized patients would want to be resuscitated

- $28(52 \%)$ say they would like family and friends to look after them

- $20(35 \%)$ prefer professional care

- 41(72\%) would like to have somebody by their side when their condition worsen

- $12(21 \%)$ want to be left on their own

- $53(93 \%)$ find it useful and helpful to address endof-life issues with a questionnaire

- $4(7 \%)$ did not find it helpful.

Summary of the results: most patients on oxygen therapy want to participate in decision making, they want to be intubated, if their survival depended on this procedure $(75 \%)$, and over $50 \%$ of participants $(55.9 \%)$ would also have a tracheostomy, most of them don't want to be left alone in difficult moments $(72 \%)$ and $93 \%$ interviewed again after one year considered the questionnaire useful and helpful.

\section{DISCUSSION}

Our study, the first in Italy asking directly patients about their preferences in chronic respiratory failure, revealed that the vast majority $(90 \%)$ of our patients, despite the common believe of many healthcare providers, wants to be informed and actively involved in end-of-life decision making, which doesn't mean, however, that all of them can take immediate decisions.

Another clinical case can illustrate this.

An "undecided" 70-year-old woman with amyotrophic lateral sclerosis said during her first interview with pulmonologists: "Please don't tell me the end". After every acute episode, she said she might agree to an invasive procedure. Everybody knew that she was torn between two fearful alternatives: dying and spending the rest of her life bed-ridden, on a ventilator and looked after by her daughters.

Her decision making process shows that expecting a simple "yes" or "no" answer from patients faced with the prospect of a procedure like tracheostomy would be unrealistic.

The woman remained "undecided" until her death one year later, repeatedly refusing NIMV and other invasive procedures, and only receiving palliative care.

End-of-life decisions are extremely difficult, painful and psychologically hard to make for all patients and their families, but also for physicians. We know that several patients are unable or refuse to make decisions, and some people wonder whether we are asking too much. According to an article from the Lille hospital in France, only $20 \%$ of the 35 patients with amyotrophic lateral sclerosis were able to provide treatment indications also in advance [8]. Our questionnaire doesn't confirm this result, partly because patients were told, during the interview, that they could change their answers at any time.

Medical decisions are seen as a "work in progress". The last question in the follow-up interview, one year later, confirmed that patients want to discuss future scenarios. We called our questionnaire "Therapeutic choices", rather than "End-of-life choices", partly because the end of life can be postponed by many years with invasive and non-invasive ventilation. Patients told us they felt relieved after being given the opportunity to freely discuss the "what-happensif-I-get-worse" issue with doctors: this way, they feel re-assured that they can rely on future support, even when the situation gets worse, and receive palliative care. Patients know, unless they repress this thinking, that support gives hope even when things turn for the worse.

Several researches show how difficult end-of-life care communication can be for patients with COPD [10]. Independent decision making is impossible, unless adequate information is available.

\section{CONCLUSIONS}

It is essential to see medical decisions in chronic disabling diseases as a process, a journey, without preconceptions in one sense or the other. Therapeutic decisions should be routinely documented.

The following key points emerge:

1. every patient has the right to be informed of all the therapeutic choices available to him and actively participate in decision making. The study showed that this is also the will of the patients;

2. enabling patients to take part in decision making and ensuring that treatments can be agreed with them requires re-organizing of the care process around patients' goals and needs: taking note of patients' will is not an on-off activity, but an ongoing process; 
3. end-of-life choices can be changed at any time during the disease: the very concept of "therapeutic alliance" entitles patients to make different choices from those they made earlier and re-assures them that healthcare professionals will respect their wishes.

4. the STIR questionnaire can help to make this difficult communication easier.

\section{References}

1. Miccinesi G, Fischer S,Paci E, Onwuteaka-Philipsen, Bregje D, Cartwright C, van der Heide A, Nilstun T, Norup M, Mortier F. Physicians' attitudes towards end-of-life decisions: a comparison between seven countries. EURELD consortium, Social science \& medicine (1982). 60(9): 1961-1974; 2005. http://dx.doi.org/10.1016/j.socscimed.2004.08.061.

2. van der Heide A, Faisst K, Nilstun T, Norup M, Paci E, van der Walt G, van der Maas PJ. End-of-life decision-making in six European countries: descriptive study. EURELD consortium. Lancet 2003362(9381):345-50. http://dx.doi.org/10.1016/S0140-6736(03)14019-6.

3. Miccinesi G, Puliti D, Paci E. End-of-life care and end-oflife medical decisions: the ITAELD study. Epidemiol Prev 2011;35(3-4):178-87.

4. Chiò A, Silani V, Italian ALS Study Group. Amyotrophic lateral sclerosis care in Italy: a nationwide study in neurological centers. J Neurol Sci 2001;191(1-2):145-50.

5. British Thoracic Society. The burden of lung disease. $2^{\circ}$ edition. London: British Thoracic Society; 2006.

6. Kerr M. Few end-stage COPD patient discuss end-of-

\section{Conflict of interest statement}

There are no potential conflicts of interest or any financial or personal relationships with other people or organizations that could inappropriately bias conduct and findings of this study.

Received on 4 April 2012.

Accepted on 24 July 2012.

life plans with physicians. Chest 2003. Slide presentation. Presented Oct. 27, 2003.

7. Wildman M J, O’Dea J, Kostopoulou O, Tindall M, Walia $\mathrm{S}$, Khan Z. Variation in intubation decisions for patients with chronic obstructive pulmonary disease in one critical care network. QJM 2003;96(8):583-91. http://dx.doi.org/10.1093/qjmed/hcg104.

8. Heffner J E, Fahy B, Hilling L, Barbieri C. Attitudes regarding advance directives among patients in pulmonary rehabilitation. Am j Respit Crit Care Med 1996;154:1735-9.

9. Danel-Brunaud V, Laurier L, Parent K, Moreau C, Defebvre L, Jacquemin D, Destée A. Issues of France's "Leonetti Act": involvement of amyotrophic lateral sclerosis patients in prior discussions concerning respiratory support and endof-life care. Rev Neurol 2009;165(2):170-7. http://dx.doi.org/10.1016/j.neurol.2008.08.008.

10. Curtis J R. Palliative and end-of-life care for patients with severe COPD. Eur Respir J 2008;32(3):796-803. Epub 2007 Nov 7. http://dx.doi.org/10.1183/09031936.00126107. 